\title{
Robertson's Mutator transposons in $A$. thaliana are regulated by the chromatin-remodeling gene Decrease in DNA Methylation (DDM1)
}

\author{
Tatjana Singer, ${ }^{1}$ Cristina Yordan, ${ }^{1}$ and Robert A. Martienssen ${ }^{2}$ \\ Cold Spring Harbor Laboratory, Cold Spring Harbor, New York 11724, USA
}

\begin{abstract}
Robertson's Mutator transposable elements in maize undergo cycles of activity and then inactivity that correlate with changes in cytosine methylation. Mutator-like elements are present in the Arabidopsis genome but are heavily methylated and inactive. These elements become demethylated and active in the

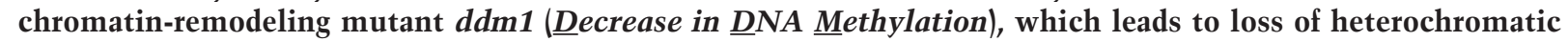
DNA methylation. Thus, DNA transposons in plants appear to be regulated by chromatin remodeling. In inbred $d d m 1$ strains, transposed elements may account, in part, for mutant phenotypes unlinked to $d d m 1$. Gene silencing and paramutation are also regulated by DDM1, providing support for the proposition that epigenetic silencing is related to transposon regulation.
\end{abstract}

[Key Words: Transposable element; heterochromatin; epigenetic; DDM1]

Received November 15, 2000; revised version accepted January 5, 2001.

Transposable elements are widespread constituents of all eukaryotic genomes. Discovered first in maize, transposons and retrotransposons occupy $50 \%-80 \%$ of this genome and frequently reach copy numbers of several thousand (SanMiguel et al. 1998; Fedoroff 1999). Most DNA transposons are no longer active and require an autonomous element in trans to transpose. In maize, cisacting transposon regulatory mechanisms are thought to include DNA methylation. Transposase promoter sequences from McClintock's Activator and SuppressorMutator transposons, for example, are hypomethylated in the active state, although the rest of the element is methylated constitutively (Banks et al. 1988; Fedoroff 1999). In vitro, transposon DNA binds more efficiently to transposase when hemimethylated than when unmethylated or fully methylated, possibly because this marks recently replicated transposons in vivo (Kunze and Starlinger 1989). For these and other reasons, we have proposed that DNA methylation is a fundamental property of transposons that differentiates them from the remainder of the genome (Martienssen 1998; Rabinowicz et al. 1999).

Robertson's Mutator transposons in maize fall into six categories, which share highly similar 200-bp terminal inverted repeats (TIRs; Bennetzen 1996). The autonomous $M u D R$ element in maize encodes two genes,

\footnotetext{
${ }^{1}$ These authors contributed equally to this work.

${ }^{2}$ Corresponding author.

E-MAIL martiens@cshl.org; FAX (516) 367-8369.

Article and publication are at www.genesdev.org/cgi/doi/10.1101/ gad.193701.
}

mudrA and mudrB. The mudrA gene encodes the MURA transposase, the mudrB gene encodes a subsidiary protein (MURB) that is not essential for somatic excision in maize (Lisch et al. 1999; Raizada and Walbot 2000). Two alternatively spliced forms of MURA, 736 and 823 amino acids (aa) in length, are found in maize (Hershberger et al. 1995). The 823 aa MURA protein can effectively bind to a conserved region in the element TIRs (Benito and Walbot 1997) and therefore probably functions as transposase. Nonautonomous elements, further designated as $\mathrm{Mu}$-elements, with intact inverted repeats are also mobilized by MURA, which binds to methylated, as well as unmethylated, motifs within the TIRs (Benito and Walbot 1997). Except for sharing similarity between TIRs, $M u$ elements are unrelated to $M u D R$ and do not encode functional transposase. Both types of elements, $M u D R$ and $M u$, are heavily methylated in inbred strains of maize. In Mutator strains, which show a high degree of transposon activity, the TIRs of $M u$ elements such as Mu1 and Mu2, as well as the TIRs of $M u D R$, are hypomethylated. Because demethylation of TIRs in MuDR elements leads to high levels of transposase gene expression, it is thought that they contain the the transposase promoter (Chandler and Walbot 1986; Chomet et al. 1991; Martienssen and Baron 1994; Hershberger et al. 1995; Bennetzen 1996). Autonomous elements can spontaneously lose activity during development, a process accompanied by methylation of TIRs. This results in plants mosaic for cells containing methylated and unmethylated elements (Martienssen et al. 1990; Martienssen and Baron 1994). 
The maize and Arabidopsis genomes differ in their organization. Transposable elements in maize (especially retroelements) are the primary constituent of intergenic DNA, outnumbering genes at least four to one (SanMiguel et al. 1998). In contrast, genes outnumber transposons by five to one in Arabidopsis, and most transposons are confined to pericentromeric heterochromatin (Lin et al. 1999; Mayer et al. 1999). Recently, an interstitial region of heterochromatin resembling a maize chromomere, or knob, has been completely sequenced (Consortium 2000). The knob was found to be composed of DNA transposons $(15 \%)$, retrotransposons $(35 \%)$, and other repeats $(21 \%)$; the remaining $29 \%$ was composed of largely silent genes. Thus, the knob region more closely resembles the maize genome than the remainder of the Arabidopsis genome. Transposons and repeats were found to be heavily methylated within the knob as they are in maize.

We set out to investigate transposon methylation in plants by isolating mutants with decreased DNA methylation (ddm) in Arabidopsis (Vongs et al. 1993). DDM1 is required for methylation of tandem repeats at the centromere and at the nucleolar organizer /Vongs et al. 1993), as well as at the heterochromatic knob (Consortium 2000). This gene encodes a SWI2/SNF2 chromatinremodeling factor (Jeddeloh et al. 1999), and loss-of-function $d d m 1$ mutations lead to immediate loss of DNA methylation from heterochromatin and gradual loss from euchromatin over successive generations of inbreeding (Kakutani et al. 1999). Here, we examine the impact of $d d m 1$ on transposon activity.

Mutator-like elements are widespread constituents of the Arabidopsis genome

We performed text queries and sequence-similarity searches of the Arabidopsis genome to catalog all ORFs related to the MURA transposase of MuDR from maize. More than 200 individual ORFs were found in $90 \mathrm{Mb}$ of completed sequence. We narrowed our search further to elements structurally related to MUDR with long TIRs and harboring intact transposase genes that might still be able to transpose. Therefore, we analyzed the flanking regions of all mined sequences with homology to the mudrA gene in order to identify TIR-sequences. Only 22 ORFs encoding a putative MURA transposase were flanked by long TIRs, as is the case with MuDR in maize (Table 1A). Unlike maize MuDR elements, none of the Arabidopsis Mutator-like elements encode a protein resembling MURB.

In a recent study, 108 Mutator-like elements were identified in 17.2 $\mathrm{Mb}$ of finished Arabidopsis sequence (Le et al. 2000). These investigators coined the term MULE (Mutator-like element) to describe genes with homology to the mudrA transposase gene and related repeats and refer to Mutator-like elements with long TIRs as TIR-MULEs (http://soave.bio.mcgill.ca/clonebase/). We have adopted this nomenclature, although only 4 of the 22 TIR-MULEs we identified can be found in their study (T3F12.12 [AtMu1] = MULE16, gi2443899;
F28J12.70 = MULE3, gi2832639; F1N21.16 = MULE24A; F9D12.2 = MULE24B, gi3319339|. We have named individual elements (AtMu1, AtMu2, etc.) which are capable of transcription or transposition, consistent with the practice in maize, snapdragon, and other plants. Because we were only interested in identifying putatively intact transposons, 200 MULEs in which no TIRs could be identified were not considered further, and we did not search for Mu-like elements with homology only to TIR sequences.

\section{Analysis of TIR and transposase homologies}

Cluster analysis of the inverted repeats (Fig. 1A, Table 1B) and of the transposase genes (Fig. 1B) showed that the Arabidopsis TIR-MULEs fell into six groups. The individual elements were single-copy, except that two copies of the AtMu1 element were found on chromosomes 1 (T11I11.3) and 4 (T3F12.12, together designated as subgroup IA), two copies of AtMu2 were found on chromosome 5 (F14I23, K2K18.2; group II), and element F20D23.2 (group V) has four copies in the Columbia genome (data not shown). Both elements of the AtMu1 class (T3F12.12, T11I11.3) and both of the AtMu2 class (F14I23, K2K18.2) share 98\% sequence identity on the nucleotide and amino acid level. Bacterial and maize mudrA genes share a 25-aa signature sequence $[\mathrm{D}-\mathrm{x}(3)$ G-(LIVMF)-x(6)-(STAV)-(LIVMFYW)-(PT)-x-(STAV)-x(2)(QR)-x-C-x(2)-H] found in a highly conserved 130-aa domain (Eisen et al. 1994). The AtMu1 (T3F12.12, T11I11.3) and AtMu2 (K2K18.2, F14I23) elements differ from this signature at a single-residue-E instead of $\mathrm{V}$ at position 13 of the motif (Fig. 1B). Because those elements most likely encode functional transposase (see results below), we propose an extended consensus pattern [D-x(3)-G-(LIVMF)-x(6)-(ESTAV)-(LIVMFYW)-(PT)-x-(STAV)$\mathrm{x}(2)-(\mathrm{QR})-\mathrm{x}-\mathrm{C}-\mathrm{x}(2)-\mathrm{H}]$. The predicted AtMu1 transposase has $36 \%$ similarity and $25 \%$ identity to the MURA transposase from maize. The remaining TIR-MULEs might be defective as a result of mutations in the conserved region of MURA or because they encode truncated transposase proteins (Fig. 1B, Table 1A).

The right and left TIR sequences of the TIR-MULEs vary in length (130 bp-356 bp) and show varying degrees of conservation. In pairwise comparisons, all TIRs-with one exception (MJG14.16) - are more closely related to each other than to any other TIR of another element (Fig. 1A). TIRA of the element MJG14.16 is more closely related to the TIRs of F15K19.3 than to its own TIRB (Fig. 1A). TIRs of individual elements share a minimum sequence identity from $67 \%$ (T13P21.5) to 97\%. (Table 1A). The most conserved TIRs, with $96 \%-97 \%$ sequence identity, are those of the AtMu1 (T3F12.12, T11I11.3) and AtMu2 (F14I23, K2K18.2; Fig. 1C). All TIR-MULEs start or end with 1-4 G nucleotides. Figure 1C shows an alignment of the first $100 \mathrm{bp}$ of TIRs of those TIRMULEs that are transcribed and show the highest sequence similarity between both TIRs.

No significant similarity to the MURA transposasebinding site in maize predicted by Benito and Walbot 
Table 1A. Summary of TIR-MULEs in Arabidopsis.

\begin{tabular}{|c|c|c|c|c|c|c|c|c|c|c|c|c|c|}
\hline Group & p Accession & $\begin{array}{c}\text { TIR-MULE } \\
\text { BAC/gene no. }\end{array}$ & chr. & $\begin{array}{c}\% \text { identity } \\
\text { TIRA } \\
\text { \& TIRB }\end{array}$ & $\begin{array}{c}\text { Length } \\
\text { TIRA/TIRB } \\
\text { (bp) }\end{array}$ & $\begin{array}{c}\text { Element } \\
\text { position } \\
\text { on } \mathrm{BAC}^{\mathrm{b}}\end{array}$ & $\begin{array}{c}\text { Length } \\
\text { element } \\
\text { (bp) }\end{array}$ & $\begin{array}{c}\text { MURA } \\
\text { gene } \\
\text { location }\end{array}$ & Strand & $\begin{array}{l}\text { Pre- } \\
\text { dicted } \\
\text { exons }\end{array}$ & $\begin{array}{c}\text { Pre- } \\
\text { dicted } \\
\text { protein- } \\
\text { length } \\
\text { (aa) }\end{array}$ & \multicolumn{2}{|c|}{ Target site duplication } \\
\hline IA & AC002983.1 & $\begin{array}{l}\text { T3F } 12.12 \\
\text { AtMu1 }\end{array}$ & 4 & $97 \%$ & $294 / 294$ & $20148-23792$ & 3645 & $20819-23250$ & + & 3 & 761 & $\begin{array}{l}\text { taaaal } \\
\text { tazat }\end{array}$ & $4 / 5$ bp imperfect \\
\hline IA & AC012680.3 & $\begin{array}{l}\text { T11:1 } 1.3 \\
\text { AtMu1 }\end{array}$ & 1 & $96 \%$ & $294 / 294$ & $11840-15489$ & 3650 & $12516-14947$ & + & 3 & 761 & $\begin{array}{l}\text { tattaaaaa' } \\
\text { tattaaaaa }\end{array}$ & 9 bp perfect \\
\hline B & $A C 007123.1$ & $\mathrm{~F} 21 \mathrm{~A} 2 \mathrm{O}_{-} \mathrm{a}$ & 5 & $95 \%$ & $277 / 278$ & $42594-46220$ & 3627 & $45556-43148$ & - & 5 & 773 & $\begin{array}{l}\text { ataatataa/ } \\
\text { ataatataa }\end{array}$ & 9 bp perfect \\
\hline B & AL021710.1 & $F 28 \mathrm{~J} 12.70$ & 4 & $86 \%$ & $191 / 161$ & $30842 \cdot 34611$ & 3769 & $31243-33492$ & + & 5 & 633 & $\begin{array}{l}\text { acaattaatc/ } \\
\text { acaattaatt }\end{array}$ & $10 \mathrm{bp}$ imperfect \\
\hline B & AC006228.4 & F5J5.13 & 1 & $85 \%$ & $289 / 287$ & $59273-64509$ & 5237 & $59785-61763$ & + & 3 & 567 & $\begin{array}{l}\text { attttaaa/ } \\
\text { attttaaa }\end{array}$ & 8 bp perfect \\
\hline H & AC007399.1 & $\begin{array}{l}\text { F14123 } \\
\text { AtMu2 }\end{array}$ & 5 & $97 \%$ & $261 / 261$ & $49883-53854$ & 3972 & $52985-49883$ & - & 3 & 743 & $\begin{array}{l}\text { tagtatcaac/ } \\
\text { tagtatcaac }\end{array}$ & 10 bp perfect \\
\hline \|I & $\mathrm{AB} 023031.1$ & $\begin{array}{l}\mathrm{K} 2 \mathrm{~K} 18.2 \\
\boldsymbol{A t} \mathrm{Mu2}\end{array}$ & 5 & $97 \%$ & $329 / 330$ & $6738-10748$ & 4011 & $9880-7481$ & - & 3 & 743 & $\begin{array}{l}\text { tagcataatt/ } \\
\text { tagcataatt }\end{array}$ & 10 bp perfect \\
\hline ॥ & AL049876.1 & $\mathrm{T} 22 \mathrm{~B} 4.180$ & 4 & $92 \%$ & $249 / 244$ & $99243-101373$ & 2131 & $101266-99528$ & - & 3 & 461 & $\begin{array}{l}\text { atcgtcaa/ } \\
\text { atcgtcaa }\end{array}$ & 8 bp perfect \\
\hline \#11 & $A C 002130.1$ & $F 1 N 21.16$ & 1 & $93 \%$ & $275 / 275$ & $88381-92825$ & 4445 & $92131-895461$ & - & 3 & 816 & $\begin{array}{l}\text { gattctaaa } \\
\text { gattctaaa }\end{array}$ & $9 \mathrm{bp}$ perfect \\
\hline$\|$ & AF 077407.1 & F9D12.2 & 5 & $88 \%$ & $285 / 283$ & $93314-98243$ & 4930 & $93735-97099$ & + & 5 & 940 & $\begin{array}{l}\text { atataaaat } \\
\text { atataaaat }\end{array}$ & $9 \mathrm{bp}$ perfect \\
\hline$\|$ & $A C 006438.3$ & F19G14.19 & 2 & $87 \%$ & $255 / 257$ & $15946-22558$ & 6613 & $17506-21460$ & + & 2 & 545 & $\begin{array}{l}\text { ttttta/ } \\
\text { ttttttg }\end{array}$ & $6 / 7$ bp imperfect \\
\hline III & AC008016.2 & $F 608$ & 1 & $86 \%$ & $260 / 258$ & $45838-50372$ & 4535 & $46271-48307$ & + & 3 & 518 & $\begin{array}{l}\mathrm{ttt} t \mathrm{y} \\
\mathrm{ttttt}\end{array}$ & 5 bp perfect \\
\hline IV & AC006067.3 & $T 13 P 21.20$ & 2 & $94 \%$ & $162 / 191$ & $16662-18766$ & 2105 & $17524-18326$ & + & 2 & 241 & 107 bp perfect & direct repeat \\
\hline IV & AB009049.1 & MCD7.9 & 5 & $77 \%$ & $185 / 203$ & $43085-46864$ & 3780 & $43892-46360$ & + & 5 & 715 & $\begin{array}{l}\text { taaaaaata } \\
\text { taaaaaata }\end{array}$ & 9 bp perfect \\
\hline$N$ & $A C 005398.2$ & $T 13 P 21.5$ & 2 & $67 \%$ & $296 / 301$ & $1682-6206$ & 4525 & $5767-3406$ & - & 5 & 430 & - & notSo \\
\hline V & $A C 007651.2$ & $F 20023.2^{6}$ & 1 & $76 \%(96 \%)$ & $\begin{array}{l}295 / 266 \\
(131 / 131)\end{array}$ & $6902-11712$ & 4811 & $10148-7273$ & - & 5 & 622 & $\begin{array}{l}\text { ataattaat } \\
\text { ataatttagt }\end{array}$ & $10 \mathrm{bp}$ imperfect \\
\hline$v$ & AC006429.3 & F15K19.3 & 2 & $75 \%$ & $272 / 271$ & $9098-13270$ & 4173 & $12902-\uparrow 1476$ & - & 4 & 212 & $\begin{array}{l}\text { ttttcaaaaac/ } \\
\text { ttttaaaac }\end{array}$ & $\begin{array}{l}11 / 9 \text { bp } \\
\text { imperfect }\end{array}$ \\
\hline v & AB017068.1 & M.JG14 16 & 5 & $75 \%$ & $155 / 134$ & $39176 \cdot 43127$ & 3952 & $42587-40191$ & - & 5 & 641 & $\begin{array}{l}\text { gtttttttc/ } \\
\text { gttttttc }\end{array}$ & $\begin{array}{l}9 / 10 \text { bp } \\
\text { imperfect }\end{array}$ \\
\hline $\mathrm{vi}$ & AC006528.4 & $\begin{array}{l}\text { F9B } 22.8 \\
\text { AtMu6 }\end{array}$ & 2 & $95 \%$ & $356 / 356$ & $30888-35590$ & 4703 & $32219-34323$ & + & 5 & 597 & $\begin{array}{l}\text { atattaatat } \\
\text { atattaatat }\end{array}$ & 10 bp perfect \\
\hline $\mathrm{vl}$ & AC007123.1 & $F 21 A 20 b$ & 5 & $90 \%$ & $294 / 294$ & $109397-114412$ & 5016 & $114064-112267$ & . & 3 & 441 & $\begin{array}{l}\text { ggatttaaaatag/t } \\
\text { gattlaaaatga }\end{array}$ & 13 bp imperfect \\
\hline $\mathrm{vl}$ & AC005693.2 & T25N22.6 & 2 & $89 \%$ & $243 / 243$ & $19540-24231$ & 4692 & $23513-20653$ & . & 4 & 558 & $\begin{array}{l}\text { cattaaaaaaca } \\
\text { cttlaaazaaza }\end{array}$ & 12 bp imperfect \\
\hline $\mathrm{vl}$ & AC007932.2 & F11A17.16 & 1 & $88 \%$ & $335 / 319$ & $58778-61749$ & 2972 & $68664-66511$ & & 7 & 490 & $\begin{array}{l}\text { tctttaaaaaa/ } \\
\text { gcttaaaaaa }\end{array}$ & t1 bp imperfect \\
\hline
\end{tabular}

${ }^{a}$ The $5^{\prime}$ TIR (TIRA) of each element was compared to the reverse complement of its $3^{\prime}$ TIR (TIRB) over the length (bp) indicated.

'Element position refers to 5 ' end of TIRA to 3 ' end of TIRB.

cPercent identity of the first $131 \mathrm{bp}$ between TIRs of this element is $96 \%$.

(1997) could be identified in any of the TIR-MULE sequences. According to the cluster analysis of multiplesequence alignments, the TIR-MULEs can be classified in two main lineages: one class comprising groups I-II, the other class containing groups III-VI (Fig. 1A). Elements belonging to neighboring groups share $\sim 50 \%$ sequence identity (Table 1B). Assuming that highly conserved pairs of TIRs are an essential requirement for transposase binding and, hence, transposition, elements with a low level of sequence identity in their TIR sequences might no longer be transactivated and therefore are probably nonfunctional. For that reason and the observed divergence between TIR-groups, the tree very likely does not reflect an evolution of different functional groups of elements but rather different stages of degeneration. We, therefore, cannot derive a meaningful consensus sequence from multiple-sequence alignments of all TIRs in order to determine conserved MURA-binding sites. Experimental analysis of TIR sequences of elements still capable of transposition, however, will undoubtedly reveal motifs important for MURA binding. Nearly all of the TIR-MULEs (20 of 22) were inserted between short direct repeats, which varied between $8 \mathrm{bp}$ and $13 \mathrm{bp}$ (Table 1A). Five of the TIR-MULEs were flanked by perfect 9-bp repeats (Table 1A), similar to the 9-bp target-site duplications (TSD) found in maize. One 
element (T13P21.20) was flanked by identical 107 bp repeats on either side. Imperfect TSDs may have resulted from local rearrangement following transposition (Taylor and Walbot 1985; Das and Martienssen 1995) or random mutation after the transposition event.

The locations of each of the TIR-MULEs are shown in Figure 2. Six TIR-MULEs are distributed along chromosome I. On chromosomes 2, 4, and 5, 13 out of 16 TIRMULEs were found within $2 \mathrm{Mb}$ of the centromeric repeats. On chromosome 4, one copy of AtMu1 was found where pericentromeric heterochromatin has been cytologically defined (Fransz et al. 2000). This bias toward heterochromatin was even more pronounced among non-TIR elements (Consortium 2000).

\section{MULEs are regulated by DDM1}

For further analysis, at least one representative element from each group was selected that had either long or well conserved TIRs $(85 \%-97 \%$ sequence identity over at least $130 \mathrm{bp}$ ) or encoded potentially full-length transposase (743-773 aa). TIR-MULE F15K19.3, however, has only $75 \%$ sequence identity between TIRs and encodes very likely a truncated protein of 212 aa. In total, we tested 12 elements: two from group IA (T3F12.12, T11I11.3), two from group IB (F21A20_a, F5J5.13), three from group II (F14I23, K2K18.2, T22B4.180), one from group III (F9D12.2), one from group IV (T13P21.20), two from group V (F20D23.2, F15k19.3), and one from group VI (F9B22.8; Tables 1A, 2). DNA gel blots indicated that all elements were partially methylated at HpaII and EcoRII restriction sites in the Columbia and Landsberg ecotypes (Fig. 3; data not shown). Overexposure of these blots indicated that AtMu1 was less methylated in Landsberg erecta (Fig. 3A). In both Columbia and Landsberg background, all 12 elements were hypomethylated in $d d m 1$ mutants (Fig. 3B; data not shown). Hypomethylation was apparent in pooled F3 seedlings from self-pollinated homozygous mutants in the $\mathrm{F}_{2}$ generation and did not change further in subsequent generations. Thus, TIR-MULEs are a primary target of DDM1.

Transcription of TIR-MULE transposase genes was examined by RT-PCR. In wild-type Columbia plants, no transcripts could be detected for any of the elements. In $d d m 1$ mutant plants, both copies of AtMu1 (Fig. 4A), both copies of the group II element AtMu2, and one other
Figure 1. Analysis of Mutator-like elements with long terminal inverted repeats (TIR-MULEs) in Arabidopsis. (A) Unrooted distance tree of the 22 TIR-MULEs identified in this study (Table 1A,B) based on terminal inverted repeat (TIR) sequences. Mutator-like elements with TIRs (TIRMULEs) have been grouped by similiarty according to the cluster analysis. Elements that transpose in $d d m 1$ strains are highlighted in red (AtMu1) and purple (AtMu6). Bootstrap values are indicated at nodes. Subgroups IA and IB (yellow) and group II (green) contain elements which are transcribed in $d d m 1$ mutants (see Table 2). (B) Alignment of a 97-aa conserved region of the Arabidopsis MURA-like transposases with the maize MURA protein. Identical amino acids are boxed in dark grey, similar in light grey. Identical amino acids from the PROSITE signature pattern are shown below the corresponding sequence. $(C)$ Alignment of TIR sequences of transcribed elements. Identical nucleotides are boxed in grey (TIRA, 5' TIR; TIRB, 3'TIR).
A

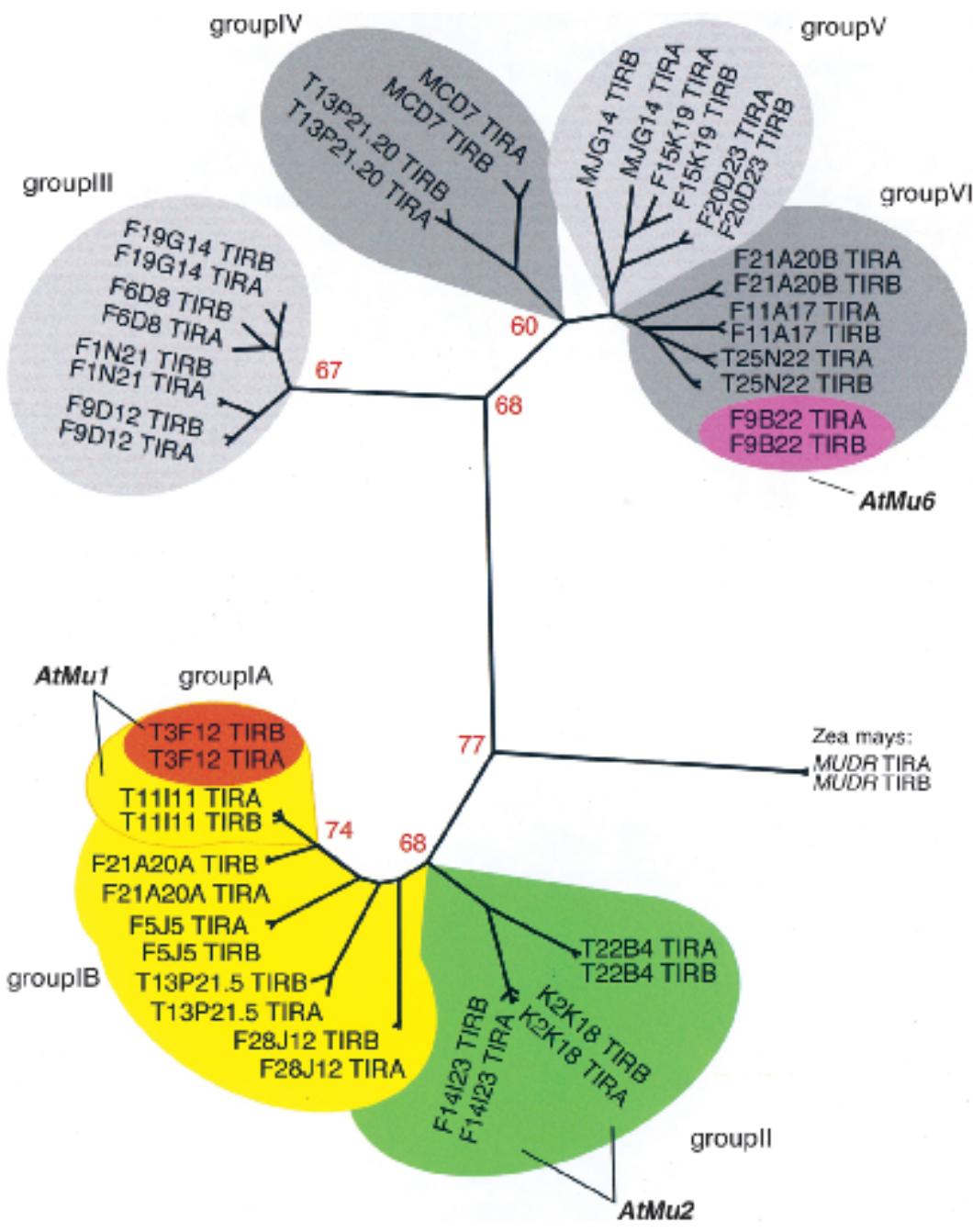


B

F28J12.70

F19G14.19

F9B22.8

F20D23.2

MCD7.9

F1N21.16

F9D12.2

T13P21.5

$\mathrm{F} 14123$

$\mathrm{K} 2 \mathrm{k} 18.2$

F5J5.13

F21A20 a

T11|11.3

T3F12.12

Maize MURA

Prosite Motif

\begin{abstract}
10
2030

40

40

50

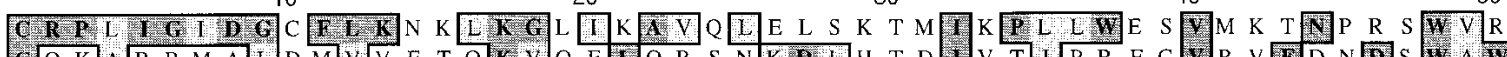

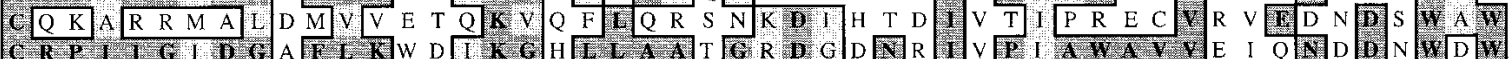

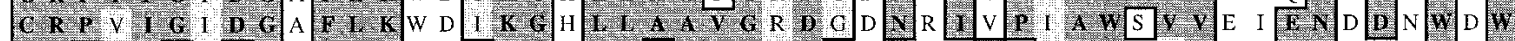

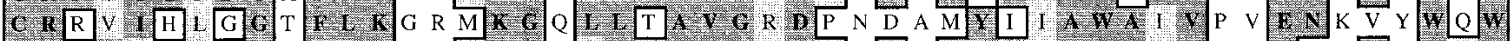

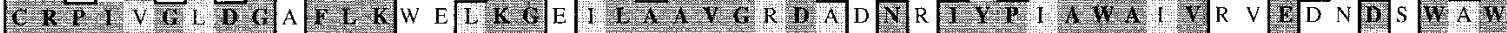

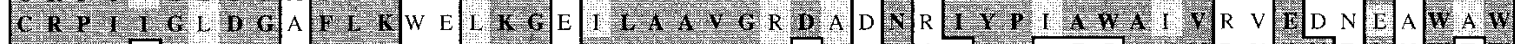
CR P T F G L D G C F L K S T L K G Q L L A A V G R Y A N W M Y PL F C A V V D V E N E D N MT W

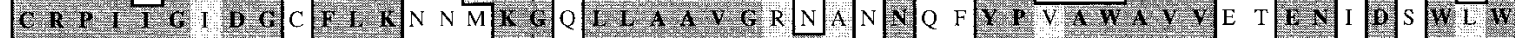

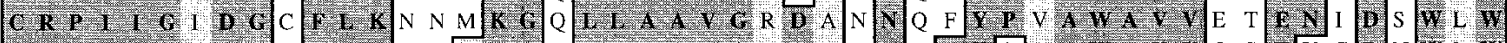

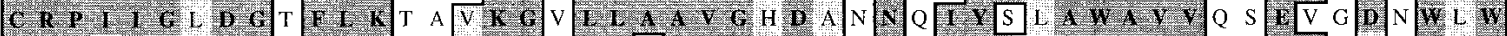

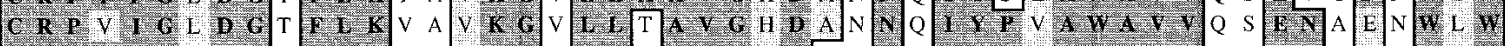

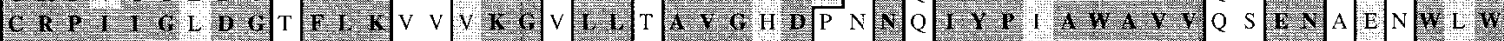

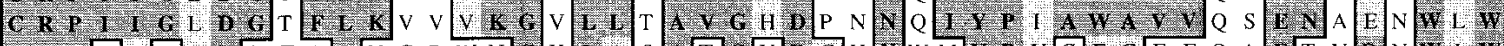

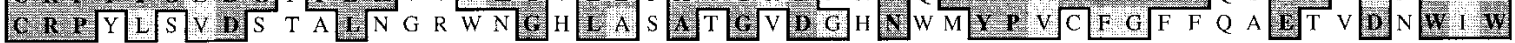

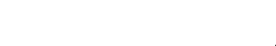

60 70

80

90

100

F28J12.70 F19G14.19 F9B22.8 F20D23.2

MCD7.9

F1N21.16

F9D12.2

T13P21.5

F14I23

K2k18.2

F5J5.13

F21A20_a

T11111.3

T3F 12.12

Maize MURA

Prosite Motif

\begin{tabular}{l}
$\mathrm{A} \quad \mathrm{F} \mathrm{Q}$ \\
\hline $\mathrm{F}$
\end{tabular}

C

F9B22.8 TIRA F9B22.8 TIRB F14I23 TIRA F14l23 TIRB K2K18.2 TIRA K2K18.2 TIRB F21A20.a TIRA F21A20.a TIRB T11I11.3 TIRA T11111.3 TIRB T3F12.12 TIRA T3F12.12 TIRB

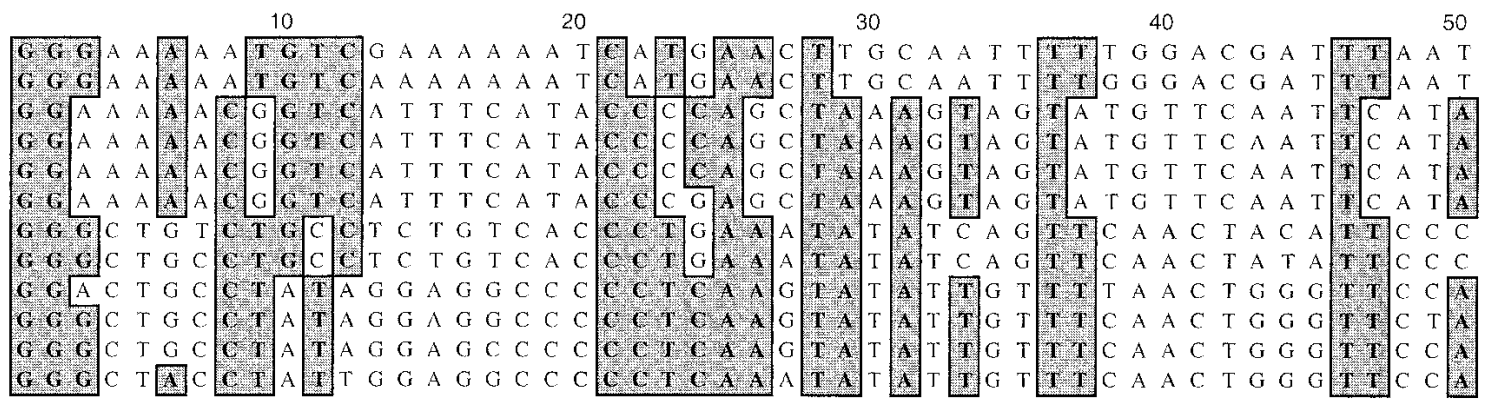

60

F9B22.8 TIRA F9B22.8 TIRB F14l23 TIRA F14I23 TIRB K2k18.2 TIRA K2K18.2 TIRB F21A20.a TIRA F21A20.a TIRB T11111.3 TIRA T11111.3 TIRB T3F12.12 TIRA T3F12.12 TIRB
70

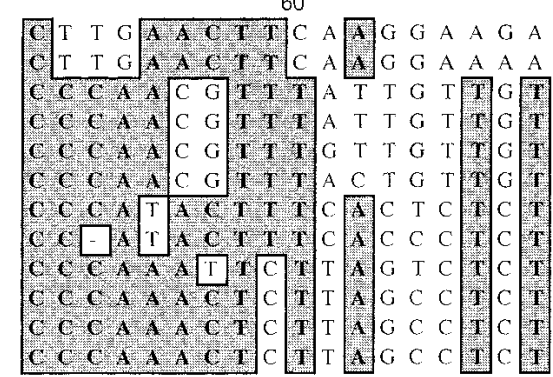

80

90

100

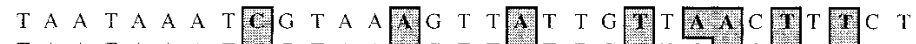
G C C A A A A T C C C C A

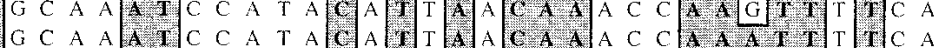

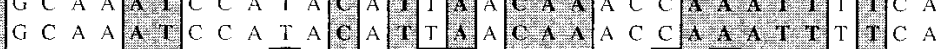

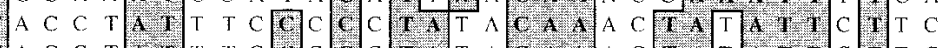

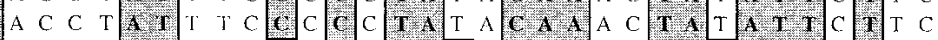

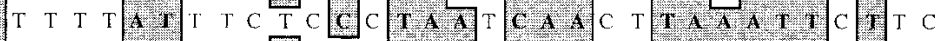

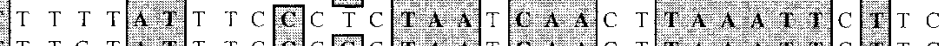

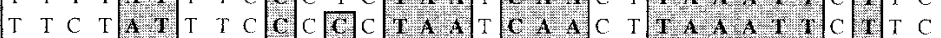

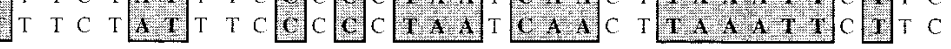

group IB element (F21A20_a) were transcribed (Fig. 4D; Table 2; data not shown). Bona fide transcription was confirmed by sequencing the RT-PCR products from AtMu1 and showing accurate splicing (see Materials and 
Table 1B. Comparison of TIRs between related TIR-MULE groups

$\%$ identity of TIRs

(100 bp)

\begin{tabular}{|c|c|c|c|}
\hline $\begin{array}{l}\text { TIR-MULE } \\
\text { group }\end{array}$ & group $(A)\left(A, u_{1}\right)$ & T F 12.12 & mean \\
\hline \multirow{5}{*}{ Group. $1 \mathrm{~B}$} & F21A20_a & $70 \%$ & \multirow{5}{*}{$58 \%$} \\
\hline & F5J5.13 & $58 \%$ & \\
\hline & T13P21.5 & $55 \%$ & \\
\hline & F28J12.70 & $47 \%$ & \\
\hline & group IB & resd12 70 & \\
\hline \multirow{3}{*}{ group 1} & $\mathrm{~F} 14 \mathrm{I} 23 / \mathrm{K} 2 \mathrm{~K} 18.2$ & $53 \%$ & \multirow{3}{*}{$48 \%$} \\
\hline & T22B 4.180 & $43 \%$ & \\
\hline & group II (ATHU2) & K2K 18 2/P 14123 & \\
\hline \multirow{5}{*}{ group nII } & F19G14.19 & $53 \%$ & \multirow{5}{*}{$50 \%$} \\
\hline & F6D8 & $50 \%$ & \\
\hline & $\mathrm{F} 1 \mathrm{~N} 21.16$ & $49 \%$ & \\
\hline & F9D 12.2 & $45 \%$ & \\
\hline & group III I : & $F 90122$ & \\
\hline \multirow{3}{*}{ group IV } & T13P21.20 & $50 \%$ & \multirow{3}{*}{$53 \%$} \\
\hline & MCD7.9 & $55 \%$ & \\
\hline & group IV & T/3P21/20 & \\
\hline \multirow{4}{*}{ group V } & F20D23.2 & $46 \%$ & \multirow{4}{*}{$47 \%$} \\
\hline & MJG14.16 & $46 \%$ & \\
\hline & $\mathrm{F} 15 \mathrm{~K} 19.3$ & $48 \%$ & \\
\hline & graup V & $\mathrm{MuG1416}$ & \\
\hline \multirow{4}{*}{ group VI } & $F 21 A 20 \mathrm{~b}$ & $52 \%$ & \multirow[b]{4}{*}{$52 \%$} \\
\hline & $\mathrm{T} 25 \mathrm{~N} 22.6$ & $53 \%$ & \\
\hline & $\mathrm{F} 11 \mathrm{~A} 17.16$ & $54 \%$ & \\
\hline & F9B22.8 & $50 \%$ & \\
\hline
\end{tabular}

TIR sequences of one representative element of each group (typed in bold in the second vertical column) were compared to TIR sequences of all of the elements of the next closest related group (designated in the first column) according to the evolutionary tree. The percentage of identity is given. Mean is the average sequence identity between groups of elements.

Methods). Interestingly, although only one AtMu1 element (T3F12.12) was present in Landsberg erecta (Fig. $4 \mathrm{~B})$, it was transcribed in $D D M 1+$ plants (Fig. 4D). The same was true of AtMu2, which is located near the centromere of chromosome 5 (Table 2). Thus, Landsberg erecta and Columbia differ in the regulation of TIRMULE transcripts.

None of the other transposase genes tested by PCR was transcribed by this assay. Expressed sequence tags (AC701558554 and H7A1T7) were found corresponding to a group-VI element (F9B22.8, AtMu6) located near the centromere of chromosome 2, which was not tested by RT-PCR (Table 2). In pairwise comparisons, all the transcribed elements share at least $95 \%$ similarity between both TIRs (Table 1A). Because multiple elements are transcribed, it is not possible to assign any one element as the source of functional transposase in $d d m 1 \mathrm{mu}-$ tants.

DNA gel blots revealed that AtMu1 was stable in $>80$ individual wild-type plants from Columbia (Table 2). Thirteen percent of individual $d d m 1$ plants had novel AtMu1 bands suggestive of transpositions (Fig. 4B,C). These bands were not found in parental Columbia DNA (Fig. 4B,C). In Landsberg, rare transpositions (1\%) were detected in wild-type plants (consistent with transcription in this ecotype) but were much more frequent $(16 \%)$ in $d d m 1$ mutants (Table 2). These frequencies of transposition are comparable to rates found for individual $\mathrm{Mu}$ elements in minimal Robertson's Mutator-lines in maize, which are equivalent to those described here (Lisch et al. 1995). In more active maize lines with multiple elements, transposition frequencies are 2-5 times higher, and $\mathrm{Mu}$ elements are also found as extrachromosomal circles (Sundaresan and Freeling 1987). We tested for such circles in Arabidopsis by DNA gel blot analysis of undigested Arabidopsis DNA but failed to detect them (data not shown). One possibility is that circular forms are transposition intermediates that require the MURB that is only found in maize. Alternatively, low copy number may prohibit detection.

In plants that did have transposed elements, no evidence of germinal excision was observed, either by Southern blotting or PCR among 25 progeny carrying the transposed element (data not shown). This suggests that germinal insertions occur without germinal excision, just as they do in maize. Further experiments using selectable assays for germinal excision are needed to make this conclusion more robust. The AtMub element F9B22.8 was transcribed but transposed only rarely in ddm1 mutants (Table 2). The transposase gene in this case is lacking the first 190 amino acids and may be nonfunctional, suggesting that this element is activated in trans.

Flanking sequences were amplified from $10 \mathrm{AtMu1}$ transpositions by adapter-ligation PCR (AIMS) and sequenced to determine their location in the genome. Insertions were verified by DNA gel blot analysis of progeny plants using the flanking sequence (data not shown) and AtMu1 as probes (Fig. 4). Amplification with element-specific primers and primers from either side of the AtMu1 insertion site, followed by sequencing of the PCR products, confirmed the location of insertions. In all cases examined, it was the AtMu1 element on chromosome 4 (T3F12.12) that had transposed. For eight of these sequences, the insertion site could be mapped to the nucleotide, and they all generated 9-bp insertion-site duplications (Table 3). One transposition integrated between T3H13.5 (HY4) and T3H13.6, only $176 \mathrm{kbp}$ distal from the AtMu1 copy on chromosome 4. The other transpositions were unlinked to the parental AtMu1 element. Consistent with these results, Mutator elements in maize do not preferentially transpose to linked sites (Lisch et al. 1995). In this small sample, there were no biases against integration within repeats, promoters, or retrotransposons. None of the transpositions disrupted predicted coding regions, but integration of 6 out of 10 AtMu1 elements within $200 \mathrm{bp}-1500 \mathrm{bp}$ upstream of predicted start codons indicated possible promoter disruption (Table 3).

Role of transposons in epigenetic regulation and genome organization

$D D M 1$ is required for silencing of methylated and re- 

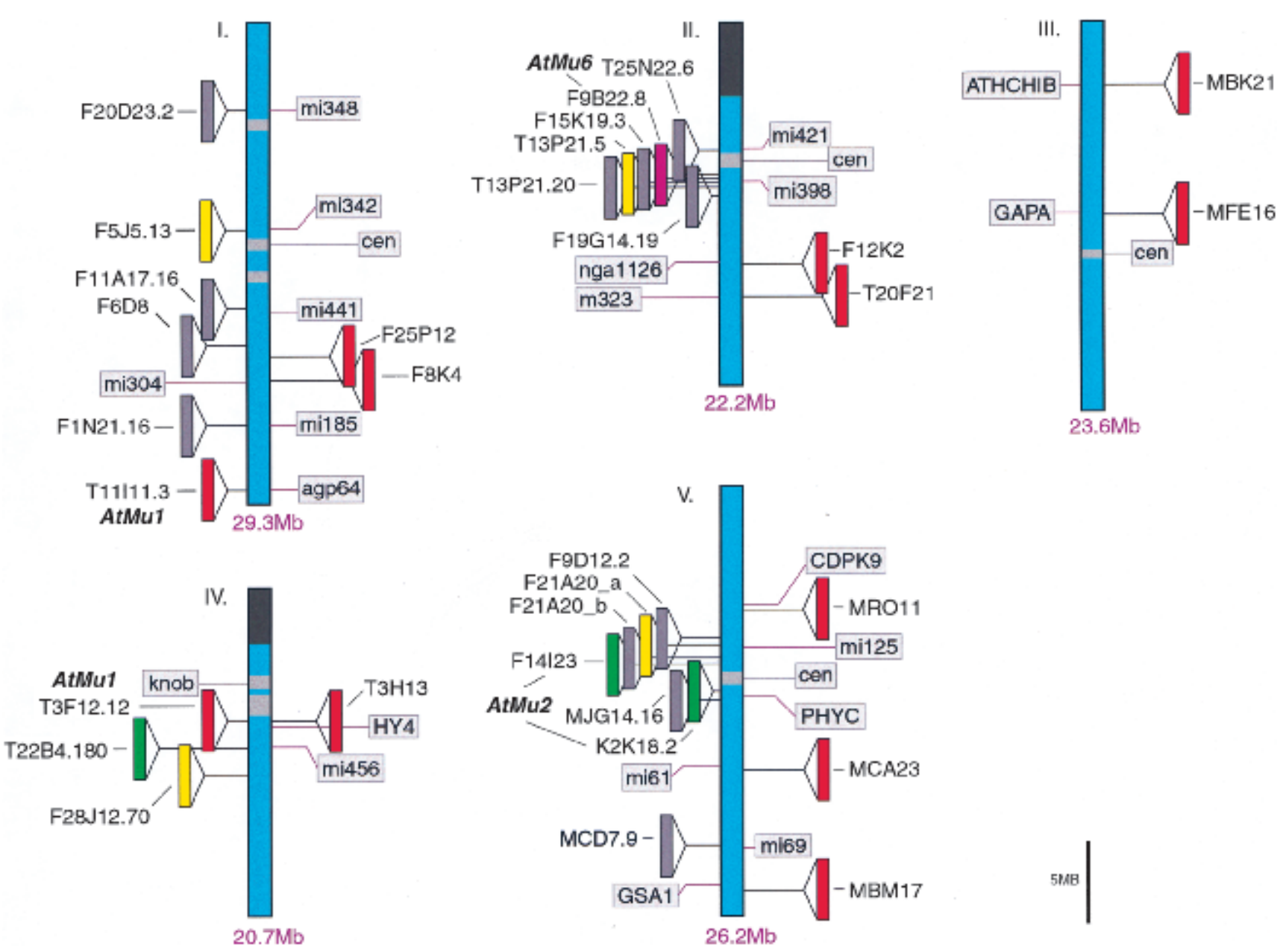

Figure 2. Genomic locations of TIR-MULE transposons. Potentially intact elements with TIRs in the Columbia ecotype are shown to the left of each chromosome. Transposed AtMu1 elements in $d d m 1$ strains are shown on the right (Table 3). Genetic markers and map positions, as well as pericentromeric (light grey) and nucleolar (dark grey) heterochromatin, are shown. TIR-MULE subfamilies are color-coded as in Fig. 1A.

peated genes in Arabidopsis (Jeddeloh et al. 1998, 1999; Paszkowski and Mittelsten Scheid 1998), which may resemble cryptic heterochromatin (Consortium 2000). For example, DDM1 mediates silencing of the PAI2 locus by an inverted duplication at the unlinked PAI1 locus (Bender and Fink 1995; Jeddeloh et al. 1998). This type of allele-specific gene silencing resembles paramutation in maize (Brink et al. 1968; Kermicle 1996; Martienssen 1996), which may involve transposons and repeats because of their influence on the expression of neighboring genes (McClintock 1965; Martienssen et al. 1990; Barkan and Martienssen 1991; Martienssen 1996; Matzke and Matzke 1998).

Repeated transgenes encoding tobacco retrotransposons also undergo silencing in Arabidopsis, and like other silent transgenes, this silencing can be reversed in ddm1 mutants (Hirochika et al. 2000). Importantly, however, only 1 of 20 endogenous retrotransposons (Tar17) was found to be transcribed in $d d m 1$ mutants, and it does not transpose at all (Hirochika et al. 2000). In a similar study, a truncated Athila transcript was in- duced in $d d m 1$ mutants, but it did not transpose and no other retrotransposons were affected (Steimer et al. 2000). Therefore, we conclude that DDM1 has little effect on retrotransposons in Arabidopsis. In the mouse, IAP (Intracisternal A Particle) retroelements are transcribed in DNA methyltransferase (dnmt1) mutants, but transposition has not been assessed (Walsh and Bestor 1999). Nearby genes can be regulated by IAP elements (Morgan et al. 1999) suggesting that retrotransposons may mediate some of the effects of demethylation (Martienssen and Richards 1995).

We have shown that TIR-MULEs in Arabidopsis are quiescent and do not transpose in the Arabidopsis strain Columbia. Quiescence is correlated with DNA methylation and a lack of transcription, although nearly identical copies of some elements may have transposed in the recent past. In contrast, TIR-MULEs are transcribed at low levels and transpose occasionally in Landsberg erecta, in which they have lower levels of DNA methylation. In loss-of-function $d d m 1$ mutants, transposon methylation was eliminated in both strains and AtMu1 
Table 2. Methylation, transcription, and transposition of selected TIR-MULES in Arabidopsis.

\begin{tabular}{|c|c|c|c|c|c|c|c|c|c|c|c|c|}
\hline \multirow[b]{3}{*}{ TIR-MULE } & \multirow[b]{3}{*}{ chr. } & & & \multicolumn{2}{|c|}{ Methylation } & \multicolumn{3}{|c|}{ Transcription } & \multicolumn{4}{|c|}{ Transposition events } \\
\hline & & \multicolumn{2}{|c|}{ Copy number } & Col & Col & Col & Ler & Col & Col & Ler & Col & Ler \\
\hline & & Col-0 & La-er & WT & $d d m 1$ & WT & WT & $d d m 1$ & WT & WT & $d d m 1$ & $d d m 1$ \\
\hline T3F12.12/ T11I1.3 AtMu1 & 4,1 & 2 & 1 & + & - & - & + & + & $0 / 88$ & $1 / 122$ & $11 / 85$ & $6 / 36$ \\
\hline F21A20_a & 5 & 1 & 0 & + & - & - & - & + & $0 / 62$ & N.D. & $0 / 50$ & N.D. \\
\hline F14I23/K2K18.2 AtMu2 & 5 & 2 & 2 & + & - & - & + & + & N.D. & N.D. & $0 / 35$ & N.D. \\
\hline T22B4.180 & 4 & 1 & 0 & $+/-$ & - & - & - & - & N.D. & N.D. & $0 / 26$ & N.D. \\
\hline T13P21.20 & 2 & 1 & 1 & + & - & - & - & - & N.D. & N.D. & $0 / 35$ & N.D. \\
\hline F20D23.2 & 1 & 4 & 2 & $+/-$ & - & - & - & - & N.D. & N.D. & $0 / 26$ & N.D. \\
\hline F5J5.13 & 1 & 1 & 1 & + & - & - & - & - & N.D. & N.D. & $0 / 26$ & N.D. \\
\hline F15K19.3 & 2 & 1 & 1 & + & - & - & - & - & N.D. & N.D. & $0 / 26$ & N.D. \\
\hline F9B22.8 AtMu6 & 2 & 1 & N.D. & + & $+/-$ & $+^{a}$ & N.D. & N.D. & N.D. & N.D. & $1 / 54$ & N.D. \\
\hline F9D12.2 & 5 & 1 & N.D. & + & - & N.D. & N.D. & N.D. & N.D. & N.D. & $0 / 40$ & N.D. \\
\hline
\end{tabular}

a Sequence of this TIR-MULE is represented in the Arabidopsis EST database.

N.D.: Not determined.

was activated resulting in high levels $10 \%-20 \%$ per generation) of transposition. Given the predicted function and phenotype of DDM1, chromatin remodeling and DNA methylation are therefore likely required for transcriptional, as well as transpositional, repression of potentially active autonomous elements. Other TIRMULEs appear to be defective and incapable of activation.

Interestingly, Tar17, Athila, AtMu1, and AtMu2 are all located in pericentromeric heterochromatin, within a few hundred kilobase of centromeric satellite repeats, and are all transcriptionally activated in $d d m 1$ mutants. Therefore, some feature of heterochromatin that depends on chromatin remodeling may be responsible for transposon regulation. McClintock

A

B

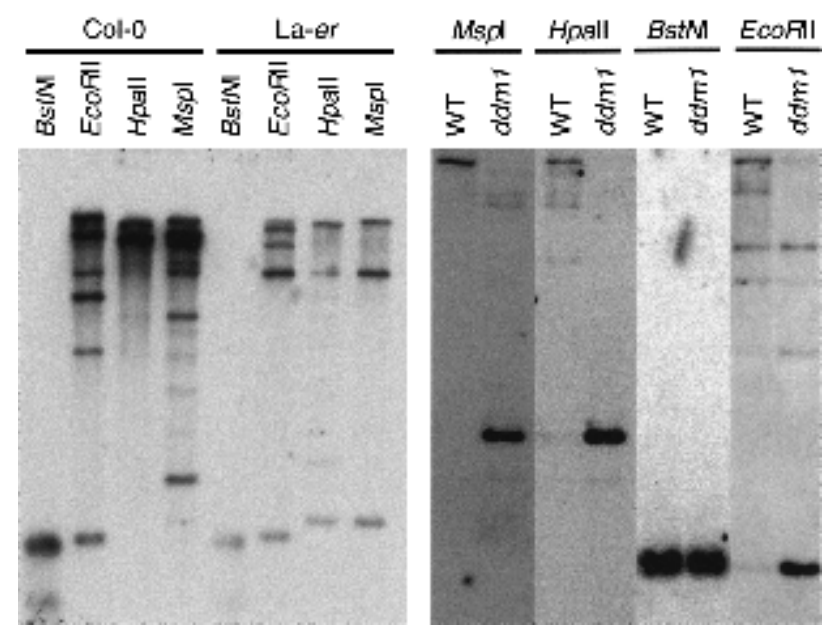

Figure 3. Mutator transposons are methylated in Arabidopsis. DNA gel blot analysis of Arabidopsis DNA from $(A)$ wild-type Landsberg erecta (La-er) and Columbia strains (Col-0) and $(B)$ wild-type and $d d m 1$ mutant plants (cv. Columbia) digested with EcoRII, BstNI, HpaII, and MspI. The blots were hybridized with probe 2 from AtMu1 (Fig. 4A).
(1951) first noted that heterochromatin underwent the same types of rearrangement as those induced by transposons. Dotted, one of the first transposons to be discovered in maize by Rhoades, was mapped to the heterochromatic knob on chromosome 9S (McClintock 1951). Dotted and other elements were activated by heterochromatic changes during the breakage-fusionbridge (BFB) cycle (McClintock 1951, 1984), and activation of heterochromatic transposons might account for genome instability in these plants (McClintock 1951). Recently, mutations in the human homolog of DDM1, the X-linked alpha-thalassemia gene $A T R X$, were shown to cause heterochromatic demethylation in a parallel manner (Gibbons et al. 2000). It will be interesting to see if human transposons are activated in these patients.

The mutator phenotype observed in $d d m 1$ lines (Kakutani et al. 1996) may be caused in part by transposition of TIR-MULEs into or near genes, but this transposon group is unlikely to account for the high frequency with which certain mutations arise in independent $d d m 1$ lines. When maize Mutator elements are inserted into promoters and introns, methylation can promote gene expression, suppressing the original mutant phenotype (Barkan and Martienssen 1991; Bennetzen 1996; Settles et al. 2001). Pre-existing insertions of MULEs, therefore, would be expected to repress nearby genes in $d d m 1$, resulting in a high frequency of epimutations at specific loci (Martienssen 1998). This model leads us to speculate on the difference between the maize and Arabidopsis genomes. Maize may be defective in certain components of the chromatin-remodeling complex that normally represses transposon activity (Martienssen and Henikoff 1999|. For example, active Mutator lines may have transacting mutations, similar to $d d m 1$, that result in the coordinate repression of multiple genes (Martienssen 1998). These mutations might influence other transposons also, consistent with the recovery of SuppressorMutator insertions in Robertson's Mutator strains in maize (Chandler et al. 1989; E. Vollbrecht and R.A. Martienssen, unpubl.). Insertional mutations are expected to 


\section{A}

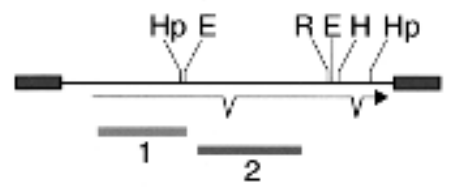

$1 \mathrm{~kb}$

C

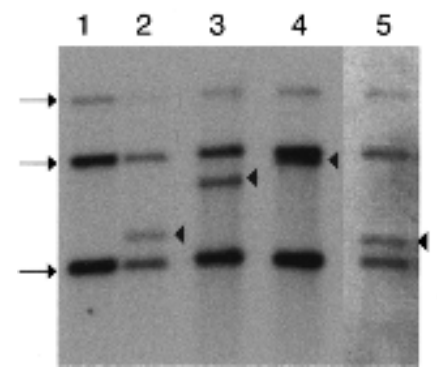

B

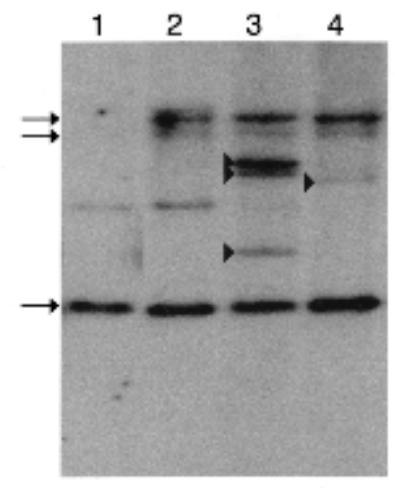

$\mathrm{D}$

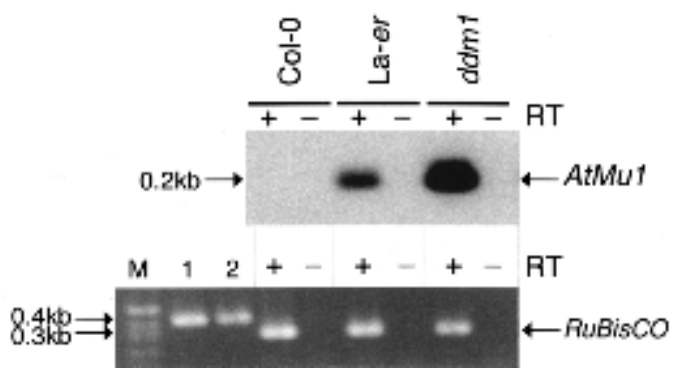

Figure 4. Mutator transposons are activated in $d d m 1$ mutants.(A) AtMu1 has 295 bp TIRs (grey boxes) and encodes three exons; probes 1 and 2 are indicated below. Restriction enzyme sites for HpaII $(\mathrm{Hp})$, HindIII $(\mathrm{H}), E c o R I(\mathrm{R})$, and EcoRII (E) are shown. (B) DNA gel blot analysis of pooled wild-type and $d d m 1$-mutant seedlings. DNA was digested with EcoRI and hybridized with probe 2 . New bands (arrowheads) represent transposition of AtMu1. The preexisting elements T11I11.3, F21A20_a, and $\mathrm{T} 3 \mathrm{~F} 12.12$ are indicated by arrows on the left. The faint band in lanes 1 and 2 is partially methylated T3F12.12. Lane 1, Landsberg erecta (Ler); lane 2, Columbia wild-type (Col-0); lane 3, Columbia $d d m 1$; lane 4, Landsberg erecta ddm1. (C) DNA gel blot analysis of individual Columbia ddm1 plants using HindIII and probe 1 . New bands (arrowheads) are transposed AtMu1. (D) RT-PCR analysis (+) of transcripts using AtMu1 primers (top panel) and control RuBisCO primers (bottom panel). Alternate lanes (-) are mock reactions in the absence of reverse transcriptase. RuBisCO lanes 1 and 2 were amplified using Col-0 and Ler genomic DNA. display extensive polymorphism in different genetic backgrounds, depending on the pattern of transposon insertion. Inbreeding would exacerbate these effects as ob- served for ddm1 (Kakutani et al. 1996), whereas mutations in different strains would complement each other, resulting in hybrid vigor (Martienssen 1998).

Table 3. Summary of transposed AtMul elements and insertion sites in ddm1 mutant plants.

\begin{tabular}{|c|c|c|c|c|c|c|c|c|}
\hline$d d m 1$-line & Ecotype & Generation & chr. & $\begin{array}{l}\text { Gene nearest } \\
\text { to insertion }\end{array}$ & Accession & $\begin{array}{l}\text { Orientation } \\
\text { of TIR-MULE }\end{array}$ & Comments & $\begin{array}{l}\text { Target site } \\
\text { duplication }\end{array}$ \\
\hline $4853 / 7$ & Col-0 & $\mathrm{F}_{3}$ & 1 & F25P12.97 & AC009323.4 & $5^{\prime}-3^{\prime}$ & $\begin{array}{l}\text { hypothetical protein, } \\
222 \mathrm{bp} \text { upstream }\end{array}$ & ttaaatctt (9bp) \\
\hline $4853 / 155$ & Col-0 & $\mathrm{F}_{3}$ & 2 & T20F21.11 & AC006068.3 & $3^{\prime}-5^{\prime}$ & $\begin{array}{l}\text { AP2 domain } \\
\text { transcription factor } \\
317 \text { bp downstream }\end{array}$ & aagtttttc (9bp) \\
\hline $4853 / 48$ & Col-0 & $\mathrm{F}_{3}$ & 2 & F12K2.19 & AC006233.3 & $3^{\prime}-5^{\prime}$ & $\begin{array}{l}\text { unknown protein, } \\
\text { 774bp upstream }\end{array}$ & ttatttaaa $(9 \mathrm{bp})$ \\
\hline $4855 / 4$ & Col-0 & $\mathrm{F}_{5}$ & 4 & Т3H13.5 & AF128396.1 & $3^{\prime}-5^{\prime}$ & $\begin{array}{l}\text { retrotransposon } \\
\text { 2524bp from HY4 }\end{array}$ & aatttatta $(9 \mathrm{bp})$ \\
\hline $4853 / 6$ & Col-0 & $\mathrm{F}_{3}$ & 5 & MBM17.4 & АВ019227.1 & $3^{\prime}-5^{\prime}$ & $\begin{array}{l}\text { protein kinase, 414bp } \\
\text { upstream }\end{array}$ & aagattctt $(9 \mathrm{bp})$ \\
\hline $4853 / 154^{\mathrm{b}}$ & Col-0 & $\mathrm{F}_{3}$ & 5 & MRO11.11 & AB005244.2 & $3^{\prime}-5^{\prime}$ & $\begin{array}{l}\text { unknown protein } \\
290 \mathrm{bp} \text { upstream }\end{array}$ & aagtatcaa $(9 b p)$ \\
\hline $4220 / 11^{\mathrm{b}}$ & Col-0 & $\mathrm{F}_{6}$ & 5 & MCA23.3 & АВ016886.1 & N.D. & $\begin{array}{l}\text { GTPase activating } \\
\text { protein }\end{array}$ & N.D. ${ }^{a}$ \\
\hline $4574 / 21$ & La-er & $\mathrm{F}_{3}$ & 1 & F8K4.9 & AC004392.1 & $5^{\prime}-3^{\prime}$ & $\begin{array}{l}\text { hypothetical protein } \\
\text { 800bp upstream }\end{array}$ & agtattatt (9bp) \\
\hline $4575 / 21$ & La-er & $\mathrm{F}_{4}$ & 3 & MBK21.21 & AB024033.1 & $5^{\prime}-3^{\prime}$ & $\begin{array}{l}\text { putative auxin- } \\
\text { regulated protein } \\
\text { 1423bp upstream }\end{array}$ & ttttttttt (9bp) \\
\hline $204 / 7^{b}$ & La-er & $\mathrm{F}_{5}$ & 3 & MFE16.2 & АВ028611.1 & N.D. & $\begin{array}{l}\text { Unknown protein, } \\
\text { downstream }\end{array}$ & N.D. ${ }^{a}$ \\
\hline
\end{tabular}

${ }^{a}$ Exact insertion site and orientation of element could not be determined.

${ }^{\mathrm{b}}$ Line extinct. 


\section{Material and methods}

Plant material

The $d d m$ 1-2 mutation which was used in this study was identified in the Columbia ecotype (Vongs et al. 1993). Homozygous seed (var. Columbia) were obtained by self-pollinating heterozygotes that had been backcrossed for at least eight generations (E. Richards, Washington University). Individual progeny were genotyped by DNA blot analysis (Vongs et al. 1993) and a homozygous mutant selected for self-pollination. Heterozygotes were backcrossed for six generations into Landsberg erecta and genotyped by progeny testing before selecting the next backcross. The plants were self-pollinated to obtain homozygotes, and individual F3 to F6 progeny were examined for DNA methylation and transposition.

\section{Informatics}

GenBank and TAIR (http://www.arabidopsis.org/blast) databases were searched, most recently in December 1999, using the key words Mutator, MuDR, and MuRA. The predicted AtMu1 mudrA-like transposase T3F12.12 was used to perform TBLASTN (BLOSUM62) and PSI-BLAST (BLOSUM45) searches of plant sequences with two rounds of iteration (Altschul et al. 1997). Gene models of unannotated Mutator-like elements were predicted with Genscan (http://CCR-081.mit.edu/GENSCAN. html). TIRs were located by aligning $4 \mathrm{~kb}$ of either side of the presumed coding sequence with BLAST2 (Tatusova and Madden 1999). Conserved 100-bp regions from the TIRs of each element were aligned using PILEUP (GCG 10.0, Madison, WI). Distance trees (GrowTree) used the UPGMA and the Tamura algorithms for correction. Parsimony trees were constructed heuristically using PAUP ${ }^{\star} 4.0 .0 \mathrm{~d} 55$ and the maize $M u D R$ element at waxy (Accession no. M76978) as the outgroup. TreeViewPPC Version 1.6.2 (Page 1996) was obtained at http:// taxonomy.zoology.gla.ac.uk/rod/rod.html. CLUSTALW analysis of a conserved 98-aa domain from the MURA transposase (Fig. 1B) was performed using MacVector6.5.1 (Oxford Molecular Group) and the BLOSUM30 matrix.

\section{DNA and RNA analysis}

Seedling, leaf, or inflorescence DNA was purified and subjected to DNA gel blot analysis as described by Vongs et al. (1993). Hybridization probes specific for AtMu1 elements were obtained by amplifying parts of the MuRA gene using the following primers: probe $1,5^{\prime}$-GTCGAGTACAATGGGGGTAAC-3' and $5^{\prime}$ - CAACAGACCCTGGGTTTTGAG-3'; probe 2, 5'-CC GAGAACTGGTTGTGGTTT-3' and 5'-TGGTGGCTGTCTC ATAGCTG-3'.

RNA was isolated from pooled $\mathrm{F}_{4}$ or $\mathrm{F}_{5}$ 20-d seedlings using Trizol reagent (Life Technologies) and DNAse treated with RQ1 DNAse according to the manufacturer. RT-PCR was performed using the OneStep RT-PCR Kit (Qiagen). RNA quality and concentration were determined by gel analysis and absorbance; $2 \mu \mathrm{g}$ of total RNA was reverse transcribed and then dilutions of the resulting cDNA were amplified using control primers for the RuBisCO gene to ensure even loading. RT-PCR was performed using primers from each of the AtMu exons. For AtMu1 these primers were T3F12.12: 5'-CCGAGAACTGGTTGTGGTTT3', 5'-GCTCTTGCTTTGGTGATGGT-3' (spanning intron 1), 5'-CAAGAGCTGTGGTGAAGCTG-3', 5'-TGCTTGAGAAG GTTGTGTGATG-3' (spanning intron 2); T11I11.3: 5' -CGCAC CACCAGAACCTATTT-3', 5' -CTTGAGAAGGTTGTGTGAT
A-3'; T11I11.3 nested: 5'-GAAGCTGGGCATAACGCATT AG-3', 5'-TCCTTCTTAGAGTTCTTCTCATC-3'. Other primer sequences are available on request. PCR products were directly sequenced using dye terminators on ABI Prism 377 sequencers. The sequences of the RT-PCR products are shown below. Exon borders correspond to the predicted splice sites of AtMu1.

Exon borders 1 and 2: Ler WT, 5'-TCTTTCAGACCGCT CAAAG/GGTCTTCTGAGTGCTGTT-3'; $d d m 1(\mathrm{Col}), 5^{\prime}$-TCT ATCAGATCGCTCAAAG/GGTCTTCTGAGTGCTGTT-3' . Exon borders 2 and 3: Ler WT, 5'-GAATGATGGCAATGAT GAG/ATTGAAAAGAAGGCTAAG-3'; $d d m 1(\mathrm{Col}), 5^{\prime}$-GAAT GATGGCAATGATGAG/ATTGAAAAGAAGGCTAAG-3'. (The splice-site junction is marked with a slash. Exon borders are underlined.)

RT-PCR products were transferred to Nylon $\mathrm{N}+$-membranes (Amersham) and hybridized with genomic probes obtained with the same primer pairs as used for RT-PCR.

\section{Amplification of flanking sequences}

Insertion sites were amplified using a modification of the AIMS technique (Frey et al. 1998) and using the following adapter oligonucleotides and primers: Adapter-upper, 5'-GA CTCATGCTTACCTAGTCCAGTTGACAGTACCATATG-3'; Adapter-lower, 5'-ATTGGAGTCTGGTATACAT-3' (phosphorylated at the $5^{\prime}$ end). Adapter primer 1 (AD-AIMS1), 5'-GACTCATGCTTACCTAGTCCAG-3'; Adapter primer 2 (ADAIMS2), 5'-GACTCATGCTTACCTAGTCCAGTTG-3'. AtMu1 specific primers: AtMu1_TIR150, 5'-GCTTGATTAATGTTG GTTAATTAC-3' (primer binds both TIRs); AtMu1_TIRA1, 5'GGGTGGAACCCAGTTGAAACAATATAC-3'; AtMu1_TIRA2, 5'-TTGAAACAATATACTTGAGGGGGG-3'; AtMu1_TIRB1, 5'-GGGTGGAACCCAGTTGAAACAATATAT-3'; AtMu1_ TIRB2, 5'-TTGAAACAATATATTTGAGGGGGC-3', (primers bind either TIRA or TIRB). Upper and lower adapters were denatured and annealed in equimolar amounts at room temperature for $>4 \mathrm{~h}$. Genomic DNA (100-300 ng) was cut with BfaI and ligated with 50 pmole reconstituted adapter for $1 \mathrm{~h}$ at room temperature and $2 \mathrm{~h}$ at $37^{\circ} \mathrm{C}$. The ligation was purified with spin columns (Qiagen) and one-tenth of the purified reaction was subjected to the PCR, using AD-AIMS1 and the specific AtMu primers and using the same cycling conditions as for secondary TAIL PCR (Liu et al. 1995), except that the buffer was supplemented with $3 \%$ DMSO. Annealing temperature was varied according to the primer $64^{\circ} \mathrm{C}$ (AtMu1_TIRA1/AtMu1_TIRB1) or $55^{\circ} \mathrm{C}$ (AtMu1_TIR150). Products were gel purified or diluted $1 / 100$ before reamplification with the second primer pair, using 35 cycles and $60^{\circ} \mathrm{C}$ annealing temperature.

\section{Acknowledgments}

We thank Eric Richards for helpful advice and for seed; Lehka Das for the Landsberg backcrosses; Lawrence Parnell, Kristin Schutz, Lei Hoon See, and W. Richard McCombie for sequence analysis; Monika Frey and Cornelia Stettner for the AIMS protocol prior to publication; and the anonymous reviewers for helpful comments on the manuscript. This work was supported by grants from the Department of Energy (DE-FG0291ER20047) and the National Science Foundation.

The publication costs of this article were defrayed in part by payment of page charges. This article must therefore be hereby marked "advertisement" in accordance with 18 USC section 1734 solely to indicate this fact. 


\section{Note added in proof}

While this manuscript was under review, a computational analysis of some of the Mutator-like elements in the Arabidopsis genome was published ( $\mathrm{Yu}$ et al. 2000).

\section{References}

Altschul, S.F., Madden, T.L., Schaffer, A.A., Zhang, J., Zhang, Z., Miller, W., and Lipman, D.J. 1997. Gapped BLAST and PSI-BLAST: A new generation of protein database search programs. Nucleic Acids Res. 25: 3389-3402.

Banks, J.A., Masson, P., and Fedoroff, N. 1988. Molecular mechanisms in the developmental regulation of the maize Suppressor-mutator transposable element. Genes \& Dev. 2: 1364-1380.

Barkan, A. and Martienssen, R.A. 1991. Inactivation of maize transposon $\mathrm{Mu}$ suppresses a mutant phenotype by activating an outward-reading promoter near the end of Mu1. Proc. Natl. Acad. Sci. 88: 3502-3506.

Bender, J. and Fink, G.R. 1995. Epigenetic control of an endogenous gene family is revealed by a novel blue fluorescent mutant of Arabidopsis. Cell 83: 725-734.

Benito, M.I. and Walbot, V. 1997. Characterization of the maize Mutator transposable element MURA transposase as a DNA-binding protein. Mol. Cell. Biol. 17: 5165-5175.

Bennetzen, J. 1996. The Mutator transposable element system of maize. Curr. Top. Microbiol. Immunol. 204: 195-229.

Brink, R.A., Styles, E.D., and Axtell, J.D. 1968. Paramutation: Directed genetic change. Paramutation occurs in somatic cells and heritably alters the functional state of a locus. Science 159: 161-170.

Chandler, V.L. and Walbot, V. 1986. DNA modification of a maize transposable element correlates with loss of activity. Proc. Nat1. Acad. Sci. 83: 1767-1771.

Chandler, V.L., Radicella, J.P., Robbins, T.P., Chen, J., and Turks, D. 1989. Two regulatory genes of the maize anthocyanin pathway are homologous: Isolation of $B$ utilizing $R$ genomic sequences. Plant Cell. 1: 1175-1183.

Chomet, P., Lisch, D., Hardeman, K.J., Chandler, V.L., and Freeling, M. 1991. Identification of a regulatory transposon that controls the Mutator transposable element system in maize. Genetics 129: 261-270.

Consortium, C.W.P.A.S. (The Cold Spring Harbor Laboratory, Washington University Genome Sequencing Center, and PE Biosystems Arabidopsis Sequencing Consortium). 2000. The complete sequence of a heterochromatic island from a higher eukaryote. Cell 100: 377-386.

Das, L. and Martienssen, R. 1995. Site-selected transposon mutagenesis at the hcf106 locus in maize. Plant Cell 7:287294.

Eisen, J.A., Benito, M.I., and Walbot, V. 1994. Sequence similarity of putative transposases links the maize Mutator autonomous element and a group of bacterial insertion sequences. Nucleic Acids Res. 22: 2634-2636.

Fedoroff, N.V. 1999. The suppressor-mutator element and the evolutionary riddle of transposons. Genes Cells 4: 11-19.

Fransz, P.F., Armstrong, S., de Jong, J.H., Parnell, L.D., van Drunen, C., Dean, C., Zabel, P., Bisseling, T., and Jones, G.H. 2000. Integrated cytogenetic map of chromosome arm $4 \mathrm{~S}$ of A. thaliana: Structural organization of heterochromatic knob and centromere region. Cell 100: 367-376.

Frey, M., Stettner, C., and Gierl, A. 1998. A general method for gene isolation in tagging approaches: Amplification of insertion mutagenised sites (AIMS). Plant J. 13: 717-721.

Gibbons, R.J., McDowell, T.L., Raman, S., O'Rourke, D.M.,
Garrick, D., Ayyub, H., and Higgs, D.R. 2000. Mutations in $A T R X$, encoding a SWI/SNF-like protein, cause diverse changes in the pattern of DNA methylation. Nat. Genet. 24: $368-371$.

Hershberger, R.J., Benito, M.I., Hardeman, K.J., Warren, C., Chandler, V.L., and Walbot, V. 1995. Characterization of the major transcripts encoded by the regulatory $M u D R$ transposable element of maize. Genetics 140: 1087-1098.

Hirochika, H., Okamoto, H., and Kakutani, T. 2000. Silencing of retrotransposons in Arabidopsis and reactivation by the ddm1 mutation. Plant Cell 12: 357-369.

Jeddeloh, J.A., Bender, J., and Richards, E.J. 1998. The DNA methylation locus DDM1 is required for maintenance of gene silencing in Arabidopsis. Genes \& Dev. 12: 1714-1725.

Jeddeloh, J.A., Stokes, T.L., and Richards, E.J. 1999. Maintenance of genomic methylation requires a SWI2/SNF2-like protein. Nat. Genet. 22: 94-97.

Kakutani, T., Jeddeloh, J.A., Flowers, S.K., Munakata, K., and Richards, E.J. 1996. Developmental abnormalities and epimutations associated with DNA hypomethylation mutations. Proc. Natl. Acad. Sci. 93: 12406-12411.

Kakutani, T., Munakata, K., Richards, E.J., and Hirochika, H. 1999. Meiotically and mitotically stable inheritance of DNA hypomethylation induced by $d d m 1$ mutation of Arabidopsis thaliana. Genetics 151: 831-838.

Kermicle, J.L. 1996. Epigenetic silencing and activation of a maize $r$ gene. In Epigenetic mechanisms of gene regulation (ed. V.E.A. Russo et al.), pp. 267-289. Cold Spring Harbor Laboratory Press, Cold Spring Harbor, NY.

Kunze, R. and Starlinger, P. 1989. The putative transposase of transposable element Ac from Zea mays L. interacts with subterminal sequences of Ac. EMBO J. 8: 3177-3185.

Le, Q.H., Wright, S., Yu, Z., and Bureau, T. 2000. Transposon diversity in Arabidopsis thaliana. Proc. Natl. Acad. Sci. 97: 7376-7381.

Lin, X., Kaul, S., Rounsley, S., Shea, T.P., Benito, M.I., Town, C.D., Fujii, C.Y., Mason, T., Bowman, C.L., Barnstead, M., et al. 1999. Sequence and analysis of chromosome 2 of the plant Arabidopsis thaliana. Nature 402: 761-768.

Lisch, D., Chomet, P., and Freeling, M. 1995. Genetic characterization of the Mutator system in maize: Behavior and regulation of $\mathrm{Mu}$ transposons in a minimal line. Genetics 139: $1777-1796$.

Lisch, D., Girard, L., Donlin, M., and Freeling, M. 1999. Functional analysis of deletion derivatives of the maize transposon $M u D R$ delineates roles for the MURA and MURB proteins. Genetics 151: 331-341.

Liu, Y.G., Mitsukawa, N., Oosumi, T., and Whittier, R.F. 1995. Efficient isolation and mapping of Arabidopsis thaliana $\mathrm{T}$ DNA insert junctions by thermal asymmetric interlaced PCR. Plant J. 8: 457-463.

Martienssen, R. 1996. Epigenetic phenomena: Paramutation and gene silencing in plants. Curr. Biol. 6: 810-813.

. 1998. Chromosomal imprinting in plants. Curr. Opin. Genet. Dev. 8: 240-244.

Martienssen, R. and Baron, A. 1994. Coordinate suppression of mutations caused by Robertson's Mutator transposons in maize. Genetics 136: 1157-1170.

Martienssen, R.A. and Richards, E.J. 1995. DNA methylation in eukaryotes. Curr. Opin. Genet. Dev. 5: 234-242.

Martienssen, R. and Henikoff, S. 1999. The House \& Garden guide to chromatin remodelling. Nat. Genet. 22: 6-7.

Martienssen, R., Barkan, A., Taylor, W.C., and Freeling, M. 1990. Somatically heritable switches in the DNA modification of $M u$ transposable elements monitored with a suppressible mutant in maize. Genes \& Dev. 4: 331-343. 
Singer et al.

Matzke, A.J. and Matzke, M.A. 1998. Position effects and epigenetic silencing of plant transgenes. Curr. Opin. Plant Biol. 1: 142-148.

Mayer, K., Schuller, C., Wambutt, R., Murphy, G., Volckaert, G., Pohl, T., Dusterhoft, A., Stiekema, W., Entian, K.D., Terryn, N., et al. 1999. Sequence and analysis of chromosome 4 of the plant Arabidopsis thaliana. Nature 402: 769-777.

McClintock, B. 1951. Chromosome organization and genic expression. Cold Spring Harbor Symp. Quant. Biol. 16: 13-47. - 1965. The control of gene action in maize. Brookhaven Symp. Biol. 18: 162-184.

- 1984. The significance of responses of the genome to challenge. Science 226: 792-801.

Morgan, H.D., Sutherland, H.G., Martin, D.I., and Whitelaw, E. 1999. Epigenetic inheritance at the agouti locus in the mouse. Nat. Genet. 23: 314-318.

Page, R.D. 1996. TreeView: An application to display phylogenetic trees on personal computers. Comput. Appl. Biosci. 12: 357-358.

Paszkowski, J. and Mittelsten Scheid, O. 1998. Plant genes: The genetics of epigenetics. Curr. Biol. 8: 206-208.

Rabinowicz, P., Schutz, K., Dedhia, N., Yordan, C., Parnell, L., Stein, L., McCombie, W., and Martienssen, R. 1999. Differential methylation of genes and retrotransposons allows shotgun sequencing of the maize genome. Nat. Genet. 23: 305-308.

Raizada, M.N. and Walbot, V. 2000. The late developmental pattern of $\mathrm{Mu}$ transposon excision is conferred by a cauliflower mosaic virus 35S-driven MURA cDNA in transgenic maize. Plant Cell 12: 5-21.

SanMiguel, P., Gaut, B.S., Tikhonov, A., Nakajima, Y., and Bennetzen, J.L. 1998. The paleontology of intergene retrotransposons of maize. Nat. Genet. 20: 43-45.

Settles, A.M., Baron, A., Barkan, A., and Martienssen, R.A. 2001. Duplication and suppression of chloroplast protein translocation genes in maize. Genetics 157: 349-360.

Steimer, A., Amedeo, P., Afsar, K., Fransz, P., Scheid, O.M., and Paszkowski, J. 2000. Endogenous targets of transcriptional gene silencing in Arabidopsis. Plant Cell 12: 1165-1178.

Sundaresan, V. and Freeling, M. 1987. An extrachromosomal form of the $M u$ transposons of maize. Proc. Natl. Acad. Sci. 84: 4924-4928.

Tatusova, T.A. and Madden, T.L. 1999. BLAST 2 Sequences, a new tool for comparing protein and nucleotide sequences. FEMS Microbiol. Lett. 174: 247-250.

Taylor, L.P. and Walbot, V. 1985. A deletion adjacent to the maize transposable element $\mathrm{Mu-1}$ accompanies loss of Adh1 expression. EMBO J. 4: 869-876.

Vongs, A., Kakutani, T., Martienssen, R.A., and Richards, E.J. 1993. Arabidopsis thaliana DNA methylation mutants. Science 260: 1926-1928.

Walsh, C.P. and Bestor, T.H. 1999. Cytosine methylation and mammalian development. Genes \& Dev. 13: 26-34.

$\mathrm{Yu}, \mathrm{Z}$., Wright, S.I., and Bureau, T.E. 2000. Mutator-like elements in Arabidopsis thaliana: Structure, diversity and evolution. Genetics 156: 2019-2031. 


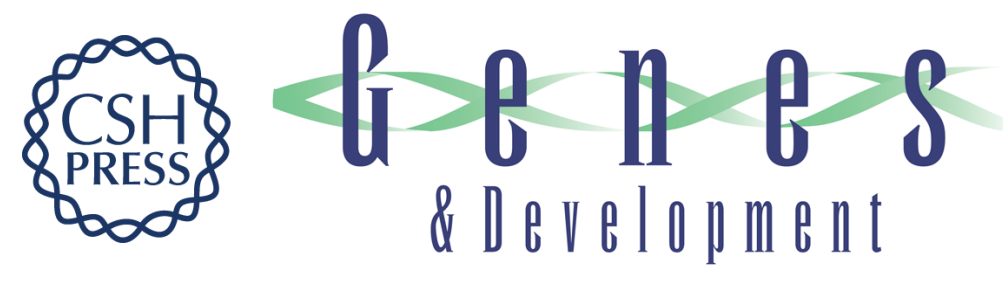

\section{Robertson's Mutator transposons in A. thaliana are regulated by the chromatin-remodeling gene Decrease in DNA Methylation (DDM1)}

Tatjana Singer, Cristina Yordan and Robert A. Martienssen

Genes Dev. 2001, 15:

Access the most recent version at doi:10.1101/gad.193701

References This article cites 54 articles, 26 of which can be accessed free at: http://genesdev.cshlp.org/content/15/5/591.full.htmI\#ref-list-1

License

Email Alerting

Receive free email alerts when new articles cite this article - sign up in the box at the top Service right corner of the article or click here.

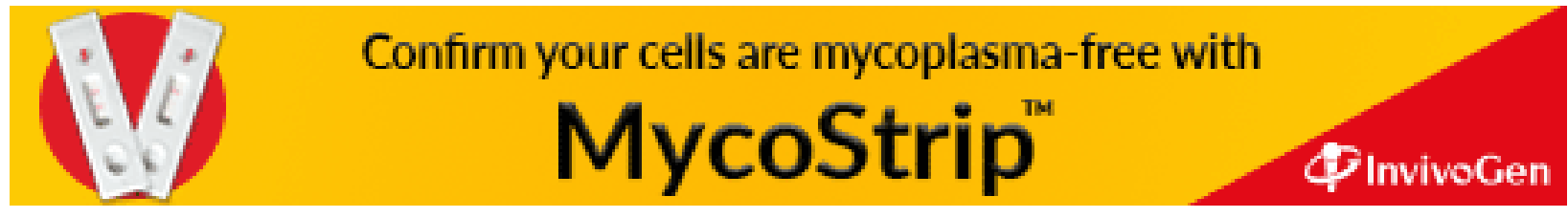

